\section{Low-Fusing Porcelain Glaze Application on 3Y-TZP Surfaces can Enhance Zirconia-Porcelain Adhesion}

Lígia Tiaki Yamamoto', Vinícius Anéas Rodrigues' ${ }^{1}$ Lucio Strazzabosco Dornelles², Marco Antonio Bottino' ${ }^{1}$, Luiz Felipe Valandro², Renata Marques de Melo ${ }^{1}$

\author{
'Department of Dental Materials \\ and Prosthodontics, Institute \\ of Science and Technology, São \\ José dos Campos Dental School, \\ UNESP - Univ Estadual Paulista, \\ São José dos Campos, SP, Brazil \\ ${ }^{2}$ Department of Prosthodontics, \\ Dental School, UFSM - \\ Universidade Federal de Santa \\ Maria, Santa Maria, RS, Brazil \\ Correspondence: Luiz Felipe \\ Valandro, Rua Floriano Peixoto, \\ 1184, 97015-372 Santa Maria, RS \\ Brazil. Tel: +55-55-3220-9276. \\ E-mail: Ifvalandro@hotmail.com
}

Key Words: surface treatment, zirconia ceramics, bond strength, nanofilm.

\section{Introduction}

The esthetics of veneering porcelain and the strength of the zirconia frameworks appears to be a successful combination for bilayered metal-free restorations. However, clinical failures of these kinds of restorations range between $13.0 \%$ at 3 years and $15.2 \%$ at 5 years (1-5).

Failures in porcelain can be caused by several conditions, such as the ceramic surface finishing, surface grinding, and inappropriate cementation technique. In bilayered restorations, the residual stress due to differences in thermal expansion coefficients of zirconia and veneer porcelain and the low thermal diffusivity of zirconia can also lead to failure (debonding) at the porcelain-zirconia interfaces (6-9).

Therefore, many studies have been carried out in an effort to improve the bond strength of the zirconiaporcelain interface with different zirconia surface treatments to reduce the amount of chipping and/or delamination of porcelain material veneered on yttriumstabilized polycrystal zirconia (3Y-TZP) (10-13).

With tribochemical silica coating by air-abrasion of silica-coated aluminum oxide particles, a silica coating is created on the surface, and roughness is increased (14). Another method is the application of a thin layer of low-fusing porcelain glaze on the zirconia, creating a graded interlayer between the zirconia/porcelain ${ }^{8}$ being an effective way to cope with the problem of deleterious delamination (8)

Another possibility is silica nano-films obtained by sputtering. The deposition process consists of accelerating argon ions against the silica target, depositing the ejected material onto the substrate (zirconia surface), with the $\mathrm{SiO}_{2}$ thin film is deposited by the magnetron sputtering PVD process, where the 3Y-TZP blocks and the silicon dioxide target are positioned in a vacuum chamber. After presputtering, the substrate holder is placed over the target, thus initiating the deposition process, controlling the time required for exposure of the substrate to the plasma to the desired film thickness. Such treatments on 3Y-TZP can create a more gradual interface between zirconia and ceramics, preventing and/or diminishing porcelain delamination and chipping (13).

Thus, the development and evaluation of new zirconia surface conditionings for zirconia-porcelain bond improvement are important for reducing the failures of restorations with $3 \mathrm{Y}$-TZP frameworks veneered by porcelain. As suggested in other studies $(8,12)$, a continuous effort for the improvement of the global mechanical behavior of porcelain-zirconia restorative systems is necessary.

There are few studies in the literature comparing the application of glaze to 3Y-TZP and veneering porcelain with the purpose of enhancing the adhesion between these materials. Thus, this work aimed to evaluate the effects 
of different zirconia surface conditioning applications on zirconia/porcelain bond strength. The null hypothesis was that there would be no differences in zirconia/porcelain bond strength via conventional ceramic treatments, treatment with silica-based nanofilm and the treatment with low-fusing porcelain glaze applications.

\section{Material and Methods}

\section{Specimen preparation}

3Y-TZP zirconia blocks ( $40 \times 19 \times 15.5$ mm; In-Ceram $Y Z$, Vita) were sectioned by means of a cutting machine diamond wheel (Isomet 1000, Buehler, Lake Bluff, IL, USA) into a square shaped specimens, which were polished with \#180-, 400-, 800- and 1200-grit silicon carbide papers under water cooling and cleaned in distilled water in an ultrasonic bath for $5 \mathrm{~min}$. Then, the specimens were sintered in a furnace (Zyrcomat T, Vita Zahnfabrik, Bad Säckingen, Germany) according to the manufacturer's directions. The final dimensions of the blocks were $12 \times 7.5 \times 1.6 \mathrm{~mm}$.

\section{Surface treatment}

The sintered blocks were randomly assigned to five groups $(n=10)$ according to surface treatment, as follows:

C group (control): No treatment was applied to the ceramic surface.

TBS group: The zirconia was airborne-particle-abraded with $30 \mu \mathrm{m}$ aluminum oxide particles (Rocatec ${ }^{\mathrm{TM}}$ Soft, $3 \mathrm{M}$ ESPE, Seefeld, Germany) at 2.5 bar pressure and a distance of $10 \mathrm{~mm}$ for $10 \mathrm{~s}$. Subsequently, a layer of silane (Monobond Plus, 3M, ESPE) was applied onto the surface for $1 \mathrm{~min}$.

GA group (glazing + hydrofluoric acid): Vita Glaze Akzent powder and liquid (VITA AKZENT, Vita Zahnfabrik) were mixed and a slurry was applied to the delimited bonding area by the silicon matrix, with the help of a brush and a first sintering was performed according to the manufacturer's instructions. Then $10 \%$ hydrofluoric acid (Dentsply, Petrópolis, Brazil) was applied for $1 \mathrm{~min}$, after which the surface was cleaned by air-water spray and gently dried.

GAS group (glazing + hydrofluoric acid + silane): The same procedure as in the GA group was performed. A layer of silane (Monobond Plus; 3M, ESPE) was then applied for $1 \mathrm{~min}$.

NF group (nanofilm): A 5-nm layer of silica-based nanofilm was applied at the Magnetism and Magnetic Materials Laboratory, UFSM (Santa Maria, Brazil), by means of the magnetron sputtering PVD process, as follows: the $3 Y$-TZP blocks and the silicon dioxide target were positioned in a vacuum chamber. The atmosphere inside the chamber was pumped down to 1027 Torr. Argon gas was admitted into the chamber at a flow rate of $20 \mathrm{sccm}$, with the pressure maintained at 5.2 mTorr. Presputtering of the target was performed, after which the substrate holder was placed over the target, thus initiating the deposition process. The deposition process consisted of accelerating argon ions against the silica target, depositing the ejected material onto the substrate (zirconia surface) located in front of the bombarded target. Time of deposition was $90 \mathrm{~s}$.

\section{Veneering Porcelain Application}

After the zirconia surface treatment, veneering porcelain cylinders were built up using a silicone template. The porcelain powder (VITA VM9 3M2 Base Dentine; Vita Zahnfabrik) was mixed with modeling liquid (Modelling Liquid; Vita Zahnfabrik) and the cylinder was constructed ( $3.3 \mathrm{~mm}$ in diameter and $3.3 \mathrm{~mm}$ in height) on the 3Y-TZP conditioned surface. The set was then sintered in a porcelain furnace (VITA VACUMAT 6000MP) and a first sintering was performed, according to the schedule recommended by the manufacturer: pre-drying at $500^{\circ} \mathrm{C}$ for $6 \mathrm{~min}$, heating to $910{ }^{\circ} \mathrm{C}$ at a rate of $55^{\circ} \mathrm{C} / \mathrm{min}$, kept under vacuum for $1 \mathrm{~min}$, cooled down to $800{ }^{\circ}$ with the oven completely closed, cooled down to $600{ }^{\circ} \mathrm{C}$ with the oven $25 \%$ open and finally cooled down to room temperature with the oven completely open.

\section{Aging Procedures}

After porcelain firing, the specimens were subjected to thermal cycling for 6.000 cycles at $55^{\circ} \mathrm{C}\left( \pm 2{ }^{\circ}\right)$ and $5^{\circ}( \pm 2$ ${ }^{\circ} \mathrm{C}$ ) with $30 \mathrm{~s} \mathrm{immersion}$ baths and transfer time from one bath to another was $2 \mathrm{~s}$.

\section{Shear Bond Strength Test}

Each specimen was embedded in acrylic resin with the adhesive interface perpendicular to the horizontal plane. Shear bond tests were performed in a universal testing machine (EMIC DL 1000, São José dos Pinhais, PR, Brazil) with a metallic device used to position the specimen in the machine. A load was applied to the adhesive interface at a constant crosshead speed of $1.0 \mathrm{~mm} / \mathrm{min}$. The specimens were subjected to shear stress by steel wire orthodontic $(\varphi=0.5 \mathrm{~mm})$ until debonding.

\section{Failure Mode Evaluation}

The fractured surfaces were analyzed bystereomicroscopy (Discovery V20; Carl-Zeiss, Gottingen, Germany) at 50x magnification and some specimens were selected for analysis by scanning electron microscopy (SEM) (Inspect S50, FEI, Hillsboro, OR, USA).

\section{Statistical Analysis}

Statistical analysis was performed with MiniTab 16 software (MiniTab Inc., State College, PA, USA). Mean and standard deviation (SD) values of shear bond strength were 
analyzed with 1-way ANOVA and Tukey's test. $p$ values less than 0.05 were considered statistically significant in all tests.

\section{Results}

One-way ANOVA showed that the zirconia-porcelain bond strength was affected by the ceramic surface treatments $(p=0.0001)$. The highest bond strength values were obtained in the groups that utilized glaze and hydrofluoric acid (GA and GAS), while the lowest bond strength value was observed in the control group (Table 1).

Failure mode analysis showed adhesive failure predominated (mainly adhesive within the zirconia) (91.66\%). Mixed failures (predominantly cohesive within the porcelain) were observed in $8.33 \%$ of the samples, and no mainly cohesive failure was found. Representative micrographs of the failures are shown in Figure 1.

SEM images showed the morphological differences on the surface of the zirconia core after surface treatments (Fig. 2).

\section{Discussion}

As reported in the literature, the most recurrent problem of zirconia-porcelain restorations is the occurrence of chipping or delamination in veneering porcelain. Surface treatments have been studied on zirconia to improve bond compatibility between the two ceramics and appear to be important to improving bond strength (13,15-19). The present work found that porcelain glaze application on the zirconia core before veneering porcelain cylinder build-up promoted zirconia-porcelain bond improvements, while the untreated group showed the lower bond strength result.

In this study, we found that the application of the glaze + hydrofluoric acid and glaze + hydrofluoric acid followed by silane (GA and GAS groups, respectively) to the zirconia surface before the application of the veneering porcelain improved bond strength. The high bond strength between the zirconia and the veneering porcelain when glaze was applied to the zirconia surface may be due to porosity created after hydrofluoric acid treatment, which

Table 1. Means $( \pm \mathrm{SD})$ in $\mathrm{MPa}$ for all groups

\begin{tabular}{lcc}
\hline Groups & $\mathrm{n}$ & $\mathrm{Mean} \pm \mathrm{SD}^{*}$ \\
\hline Control (C) & 10 & $10.1 \pm 4^{\mathrm{c}}$ \\
Tribochemical silica coating (TBS) & 7 & $12.4 \pm 4.5^{\mathrm{bc}}$ \\
Glaze + HF (GA) & 10 & $19.5 \pm 3^{\mathrm{a}}$ \\
Glaze + HF + Sil (GAS) & 10 & $16.2 \pm 4^{\mathrm{ab}}$ \\
Nanofilm (NF) & 11 & $12.0 \pm 3.5^{\mathrm{bc}}$ \\
\hline
\end{tabular}

Different letters indicate no statistically significant difference (Tukey's test; $\mathrm{p}<0.05$ ). allowed for a better micromechanical interlocking between the materials (10). Glazing the zirconia surface before the application of the porcelain may be analogous to the application of a wash dentin layer, as suggested by the manufacturer, which improves the interaction with zirconia and at the same time increases its wettability to receive the porcelain layers. This can be explained by the interdiffusion of glass on zirconia before veneering porcelain as shown in Raman spectra where some chemical elements such as silicon, sodium, aluminum and potassium diffused in the zirconium dioxide layer. This is possible because of defects in the crystalline solid (20).

Airborne particle abrasion with silica-coated aluminum oxide is considered an excellent treatment to improve the bond strength between zirconia and resin cement, through the creation of micromechanical retention on the zirconia surface $(21,22)$. Aluminum oxide particles coated with silica, 30 microns at 2.5 bar pressure were chosen due to less damage, leading to minor phase transformation $(14,23)$. In this work, silica deposition may not have been adequate to optimize adhesion, since it may have melted due to the high temperature of porcelain sintering. In addition, this procedure can induce micro-cracks at the inter-granular level, which may impair restoration longevity. In comparison it with glaze application, the latter does not result in surface damage and improves adhesion between the ceramics by siliceous oxides present in the composition.

With regard to the silane use, although it is part of a protocol related to resin bonding to zirconia, our belief was that the polymeric molecules would partially evaporate and the remaining silica would assist adhesion. This assumption was not confirmed though.

The advantages of the nanofilm technique include fast and controlled silica deposition at low temperature, compared with low fusing glass application. In addition, the thickness and chemical composition of the film can also be controlled. Another positive factor of the nano-coating is its nanometer thickness $(13,19)$. A previous study showed that nanofilm could be a favorable alternative to the deposition of silica on the Y-TZP (13), promoting high bonding strength among ceramics. The disadvantage of this technique is the requirement for specific equipment, whereas GA, GAS and $\mathrm{CJ}$ groups require only routine laboratory equipment. Our results showed that this method did not improve the bonding between the materials, probably as a result of changes in the film at high temperatures.

In terms of bond test, as it is known, the shear test is a simple test to evaluate bond strength between substrates and adherents (for instance, ceramic/ceramic or ceramic/ cement interfaces), but it presents limitations as the inhomogeneous stress distribution and high percentages of cohesive failures, therefore it has been criticized in the 
literature (24-27). In spite of that, considering that the Y-TZP substrate that has a high crystalline content and is very hard, the obtaining of sticks for microtensile test was not considered. To minimize the limitations in stresses distribution at bond interfaces, we used steel wire, which leads to better stress distribution during the shear test (24).
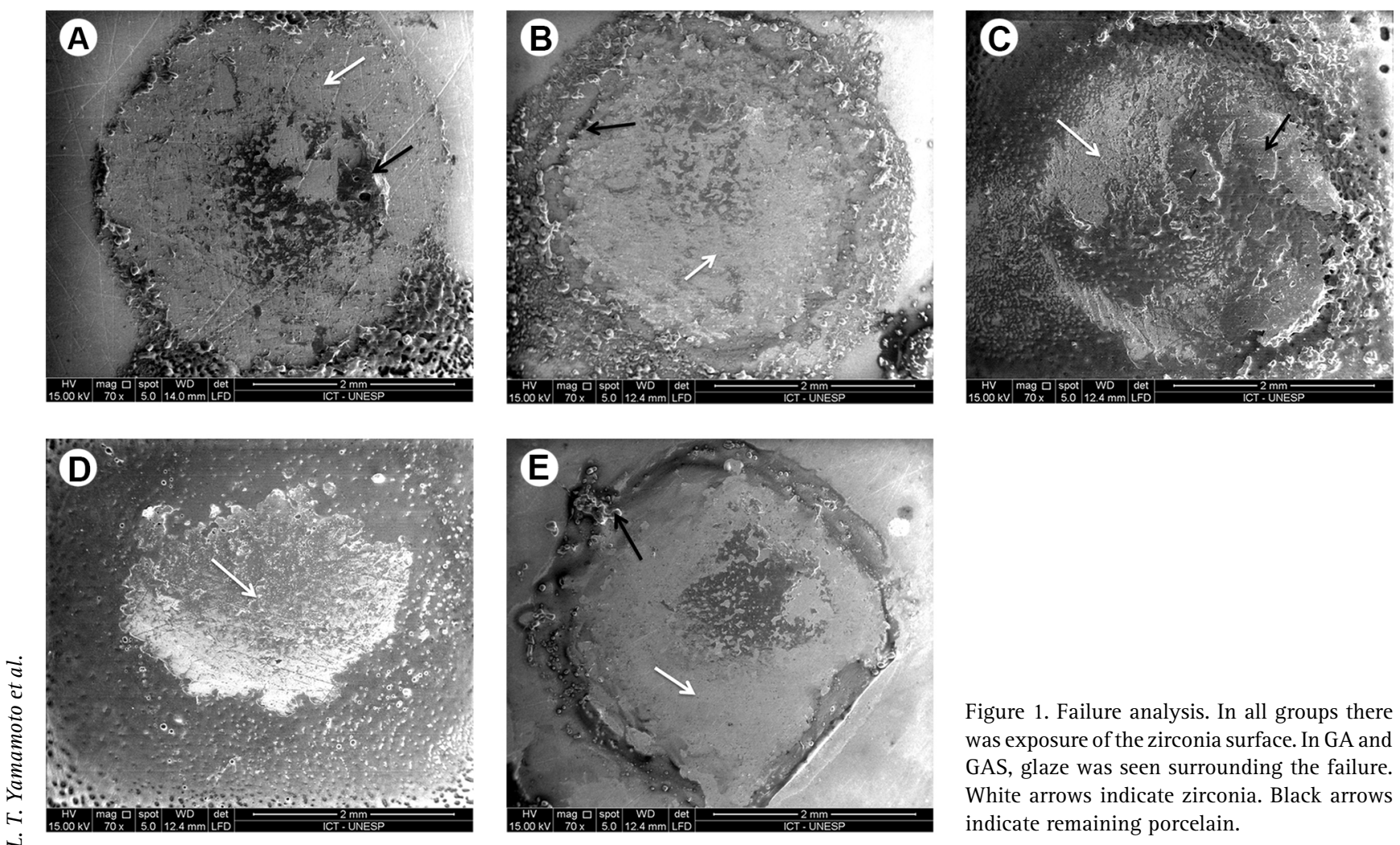

Figure 1. Failure analysis. In all groups there was exposure of the zirconia surface. In GA and GAS, glaze was seen surrounding the failure. White arrows indicate zirconia. Black arrows indicate remaining porcelain.
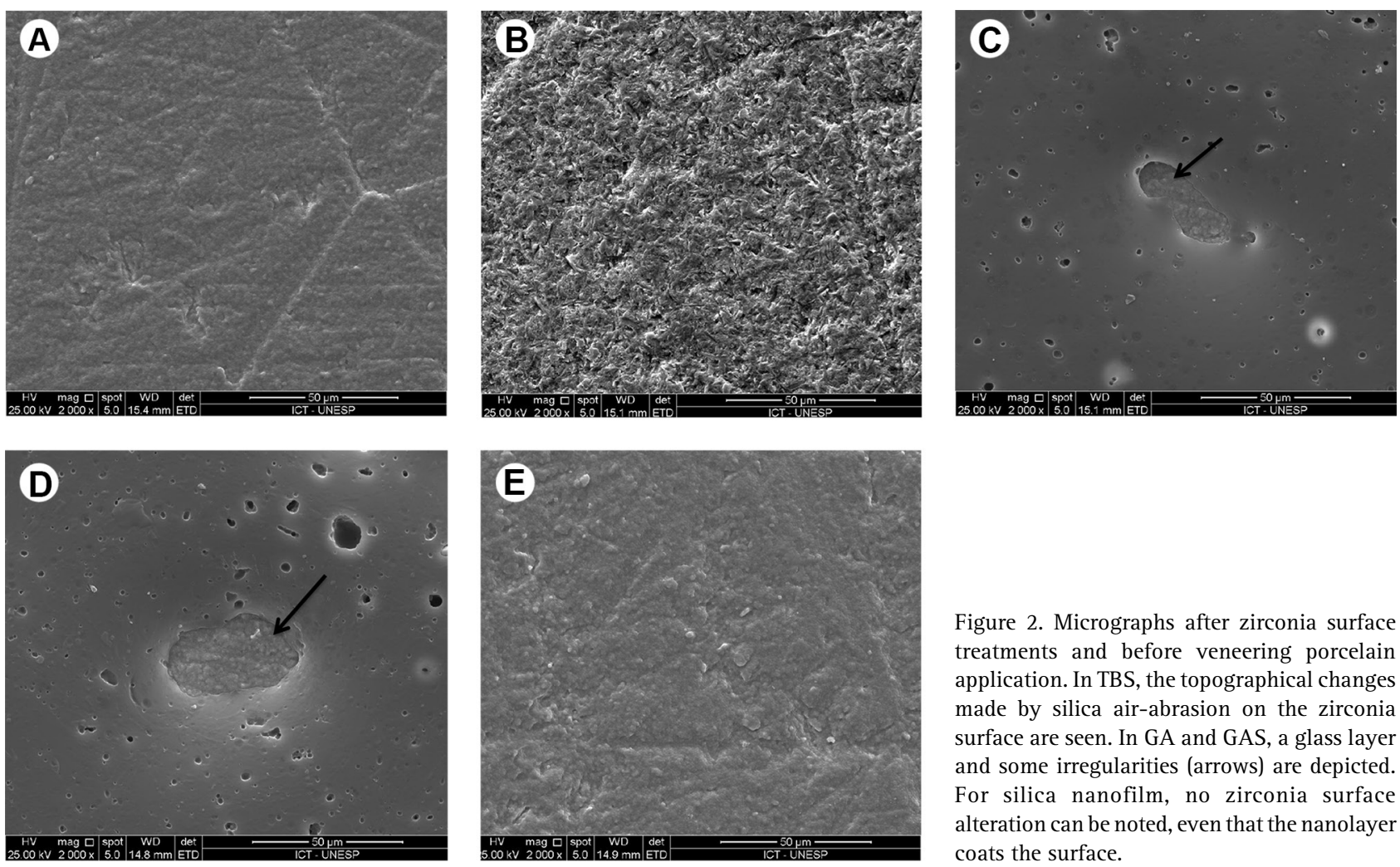

Figure 2. Micrographs after zirconia surface treatments and before veneering porcelain application. In TBS, the topographical changes made by silica air-abrasion on the zirconia surface are seen. In GA and GAS, a glass layer and some irregularities (arrows) are depicted. For silica nanofilm, no zirconia surface alteration can be noted, even that the nanolayer coats the surface. 
Further studies should consider the inclusion of a wet environment and fatigue when porcelain-zirconia crowns are tested.

In conclusion, the application of a layer of porcelain glaze is a viable alternative for improving the zirconiaporcelain adhesion.

\section{Resumo}

0 objetivo do estudo foi avaliar o efeito de tratamentos de superficie para melhora a união entre zircônia-porcelana. Os materiais testados foram 3Y-TZP e VM9. Os blocos de 3Y-TZP foram cortados em quadrados, polidos e sinterizados. Os tratamentos de superficie foram: Rocatec soft e aplicação de silano (TBS), vitrificação e ácido fluorídrico (GA), vitrificação, ácido fluorídrico e aplicação de silano (GAS), deposição de nanofilme de sílica (NF) e ausência de tratamento (C). Após os tratamentos, cilindros de porcelana foram construídos sobre as amostras e sinterizados. Após a sinterização da porcelana, todas as amostras foram submetidas a ciclos térmicos (6000 ciclos). Em seguida, os espécimes foram acoplados em uma máquina de ensaio universal e foi realizado o teste de micro cisalhamento a uma velocidade de $1,0 \mathrm{~mm} / \mathrm{min}$. As fraturas foram analisadas por estereomicroscópio e MEV. Os dados foram submetidos à ANOVA 1 fator e teste de Tukey (5\%). A resistência de união zircôniaporcelana foi afetado pelos tratamentos de superfície de cerâmica $(p=0,0001)$. GA e GAS registraram os maiores valores de resistência de união, os valores mais baixos de resistência de união foram observados no grupo $C$ (ausência de tratamento) $\left(19,5 \pm 3^{\mathrm{a}}, 16,2 \pm 4^{\mathrm{ab}}\right.$ e $10,1 \pm 4^{\mathrm{c}}$ respectivamente). Houve predominância de falhas adesivas. Portanto, a vitrificação pode ser considerada uma opção para aumentar a resistência de união entre zircônia-porcelana.

\section{References}

1. Naenni N, Bindl A, Sax C, Hammerle C, Sailer I. A randomized controlled clinical trial of 3-unit posterior zirconia-ceramic fixed dental prostheses (FDP) with layered or pressed veneering ceramics: 3-year results. J Dent 2015;43:1365-13670.

2. Anusavice KJ. Standardizing failure, success, and survival decisions in clinical studies of ceramic and metal-ceramic fixed dental prostheses. Dental Mater 2012;28:102-111.

3. Sailer I, Gottnerb J, Kanelb S, Hammerle CH. Randomized controlled clinical trial of zirconia-ceramic and metal-ceramic posterior fixed dental prostheses: a 3-year follow-up. Int J Prosthod 2009;22:553-560.

4. Raigrodski AJ, Chiche GJ, Potiket N, Hochstedler JL, Mohamed SE, Billiot $\mathrm{S}$, et al.. The efficacy of posterior three-unit zirconium-oxide-based ceramic fixed partial dental prostheses: a prospective clinical pilot study. J Prosthet Dent 2006;96:237-244.

5. Sailer I, Feher A, Filser F, Luthy H, Gauckler $\sqcup$, Scharer $P$, et al.. Prospective clinical study of zirconia posterior fixed partial dentures: 3-year follow-up. Quintessence Int 2006;37:685-693.

6. De Jager N, Pallav P, Feilzer AJ. The influence of design parameters on the FEA-determined stress distribution in CAD-CAM produced allceramic dental crowns. Dent Mater 2005;21:242-251.

7. Baldassarri M, Zhang Y, Thompson VP, Rekow ED, Stappert CF. Reliability and failure modes of implant-supported zirconium-oxide fixed dental prostheses related to veneering techniques. J Dent 2011;39:489-498.

8. Chai H, Lee JJ, Mieleszko AJ, Chu SJ, Zhang Y. On the interfacial fracture of porcelain/zirconia and graded zirconia dental structures. Acta Biomater 2014;10:3756-3761.

9. Wang $G$, Zhang $S$, Bian $C$, Kong H. Interface toughness of a zirconia- veneer system and the effect of a liner application. J Prosthet Dent 2014;112:576-583

10. Aboushelib MN. Evaluation of zirconia/resin bond strength and interface quality using a new technique. J Adhes Dent 2011;13:255260.

11. Valentino TA, Borges GA, Borges LH, Platt JA, Correr-Sobrinho L. Influence of glazed zirconia on dual-cure luting agent bond strength. Oper Dent 2012;37:181-187.

12. Diniz AC, Nascimento RM, Souza JC, Henriques BB, Carreiro AF. Fracture and shear bond strength analyses of different dental veneering ceramics to zirconia. Mater Sci Eng C Mater Biol Appl 2014;38:79-84.

13. Druck CC, Pozzobon JL, Callegari GL, Dorneles LS, Valandro LF. Adhesion to Y-TZP ceramic: Study of silica nanofilm coating on the surface of Y-TZP. J Biomed Mater Res Part B 2015:103B:143-150

14. Souza RO, Valandro LF, Melo RM, Machado JP, Bottino MA, Ozcan M. Air-particle abrasion on zirconia ceramic using different protocols: effects on biaxial flexural strength after cyclic loading, phase transformation and surface topography. J Mech Behav Biomed Mater 2013;26:155-163.

15. Aboushelib MN, Kleverlaan CJ, Feilzer AJ. Microtensile bond strength of different components of core veneered all-ceramic restorations. Part II: Zirconia veneering ceramics. Dent Mater 2006;22:857-863.

16. Kim HJ, Lim HP, Park YJ, Vang MS. Effect of zirconia surface treatments on the shear bond strength of veneering ceramic. J Prosthet Dent 2011;105:315-322.

17. Harding AB, Norling BK, Teixeira EC. The effect of surface treatment of the interfacial surface on fatigue-related microtensile bond strength of milled zirconia to veneering porcelain. J Prosthodont 2012;21:346-352.

18. Kirmali O, Akin H, Ozdemir AK. Shear bond strength of veneering ceramic to zirconia core after different surface treatments. Photomed Laser Surg 2013;31:261-268.

19. Vanderlei A, Bottino MA, Valandro LF. Evaluation of resin bond strength to yttria-stabilized tetragonal zirconia and framework marginal fit: comparison of different surface conditionings. Oper Dent 2014;39:5063.

20. Durand JC, Jacquot B, Salehi H, Fages M, Margerit J, Cuisinier FJ. Confocal Raman microscopic analysis of the zirconia/feldspathic ceramic interface. Dent Mater 2012;28:661-671.

21. Baldissara $\mathrm{P}$, Querze $M$, Monaco $C$, Scotti R, Fonseca RG. Efficacy of surface treatments on the bond strength of resin cements to two brands of zirconia ceramic. J Adhes Dent 2013;15:259-267.

22. Bielen V, Inokoshi M, Munck J, Zhang F, Vanmeensel K, Minakuchi S, et al. Bonding Effectiveness to Differently Sandblasted Dental Zirconia. J Adhes Dent 2015;17:235-242.

23. Hallmann L, Ulmer $\mathrm{P}$, Reusser $\mathrm{E}$, Hammerle $\mathrm{CH}$. Surface characterization of dental Y-TZP ceramic after air abrasion treatment. J Dent 2012;40:723-735.

24. Braga RR, Meira JB, Boaro LC, Xavier TA. Adhesion to tooth structure: a critical review of "macro" test methods. Dental Mater 2010;26:e38-e49.

25. Rasmussen ST. Analysis of dental shear bond strength tests, sheer or tensile? Int J Adhes Adhes 1996;16:147-154.

26. El Zohairy AA, Gee AJ, Jager $N$, van Ruijven $\mathrm{D}$, Feilzer AJ. The influence of specimen attachment and dimension on microtensile strength. J Dent Res 2004;83:420-424.

27. Placido E, Meira JBC, Lirna RG, Muench A, Souza RM, Ballester RY. Shear versus micro-shear bond strength test: $A$ finite element stress analysis. Dental Mater 2007;23:1086-1092. 